\title{
IMPORTED INSECTICIDE RESISTANCE IN DIAMONDBACK MOTH
}

\author{
D.G. VOICE and R.B. CHAPMAN \\ Soil, Plant and Ecological Sciences Division, P.O. Box 84, \\ Lincoln University, Canterbury
}

\begin{abstract}
Laboratory experiments were conducted to determine whether resistance in an Australian population of diamondback moth could be conferred to a local susceptible population of diamondback moth (Plutellaxylostella). Bioassays with larvae showed a 715-fold difference in response at the $\mathrm{LC}_{50}$ to alpha-cypermethrin between the resistant imported and local susceptible populations. The response of a hybrid strain from these populations displayed a lower level of resistance, and a backcross of hybrids with the parents an even lower level of resistance. The hybrid strain did not suffer any fitness disadvantage when compared with the parents.
\end{abstract}

Keywords: Plutellaxylostella, resistance, alpha-cypermethrin, bioassay.

\section{INTRODUCTION}

Diamondback moth, Plutella xylostella (L.), is an economically important pest of brassicas throughout the world. On vegetable brassicas, control has traditionally relied on regular application of insecticides, but resistance to most major classes of insecticides has now occurred (Talekar and Shelton 1993).

Until recently, resistance in diamondback moth populations to insecticides in New Zealand had not been authoritatively documented. Bell and Fenemore (1990) reported low levels of resistance to some insecticides, but this was considered insufficient to result in control failures. Higher levels of resistance to organophosphate and pyrethroid insecticides have now been detected and control failures are known (Cameron et al. 1997). By contrast, high levels of resistance in diamondback moth are common in the Australian states of Queensland (Heisswolf 1994), Victoria (Endersby and Ridland 1994) and South Australia (Baker 1994).

The potential for diamondback moth to develop resistance in one region and for it to spread to another has been identified (Talekar and Shelton 1993). For New Zealand, the risk of 'imported' resistance for diamondback moth has also been recognised (Chapman 1990). Two potential routes for the entry of resistant insects into New Zealand are through natural spread by the westerly air currents from Australia and on imported brassicas. From time to time broccoli, a favoured host of diamondback moth, is imported from Australia when Christchurch supplies are low.

This study investigates the potential to transfer resistance from a resistant Australian population to a local susceptible population of diamondback moth. The responses of the parent populations and the resulting hybrids to a commonly used pyrethroid insecticide were determined using laboratory bioassays. Whether the hybrids showed any difference from the parents with respect to larval and pupal development, adult longevity and fecundity was also investigated.

\section{Importation of diamondback moth on broccoli \\ MATERIALS AND METHODS}

To determine the extent to which broccoli imports from Australia were infested with live diamondback moth, MAF Quarantine Produce Reports were searched. The number of broccoli consignments imported, the total weight of broccoli imported and the number of infested consignments from 1995 to 1998, inclusive, were recorded. 


\section{Source of insects}

A local population of diamondback moth was sampled from a spray-free brassica crop at Harewood near Christchurch. Over 200 individuals were collected to establish the 'susceptible reference strain' colony. A sample of an Australian population was obtained from an $8 \mathrm{~kg}$ box of broccoli from a Brisbane market. This broccoli was reputedly grown in the Gatton region about $60 \mathrm{~km}$ from Brisbane. About 100 individuals were used to establish the 'imported resistant strain'. Both colonies were maintained on broccoli plants in separate controlled temperature rooms at $25^{\circ} \mathrm{C}$ and a 16L:8D photoperiod.

\section{Bioassays}

A leaf dip bioassay similar to that described by Tabashnik and Cushing (1987) was used to determine the responses of the susceptible reference strain, the imported resistant strain and the resulting hybrid strains to alpha-cypermethrin (Dominex 100 $\mathrm{g} / \mathrm{litre} \mathrm{EC})$. Broccoli leaf discs (4.75 mm diameter) were dipped for $5 \mathrm{~s}$ in an aqueous suspension of insecticide and surfactant $(2.5 \mathrm{ml} /$ litre Citowett $)$. There were five or six concentrations of insecticide and a water plus surfactant control. Each concentration was replicated five to eight times. Once the leaf discs had dried, they were placed individually into $50 \mathrm{~mm}$ diameter petri dishes and 10 third instar larvae were transferred to each dish. Mortality was assessed after $48 \mathrm{~h}$ at $25^{\circ} \mathrm{C}$; moribund larvae were also considered dead. For each bioassay, the data for each replicate were pooled and analysed by probit analysis using the program POLO (Roberston et al. 1980). The slope $( \pm \mathrm{SE})$ of the regression line, $\mathrm{LC}_{50}$ (and $95 \%$ confidence intervals) and resistance ratio $(\mathrm{RR})\left(\mathrm{LC}_{50}\right.$ resistant strain $\div \mathrm{LC}_{50}$ susceptible strain) were calculated.

\section{Hybrid strains}

Pupae collected from the susceptible and resistant strains were reared individually in petri dishes and their sex determined. Reciprocal crosses of 50 adults of each sex were made between the strains and the resulting progeny tested for their response to alpha-cypermethrin. The progeny of reciprocal back crosses between the parents (50 of each sex) of the hybrid strain and the susceptible reference strain were tested for their response to alpha-cypermethrin.

To determine whether the hybrid strain exhibited lower fitness than the parent strains, five replicated virgin pairs of these strains were reared simultaneously at $20^{\circ} \mathrm{C}$ in separate cages. The duration of larval and pupal development, the number of live moths produced by each pair and their longevity were determined. The data were analysed by one-way ANOVA.

\section{RESULTS \\ Importation of diamondback moth on broccoli}

In 1995,51 consignments totalling $74,230 \mathrm{~kg}$ of broccoli were imported from Australia. Eleven $(22 \%)$ were infested with live diamondback moth. The respective figures for the following three years were: 1996, 7 consignments, $8,981 \mathrm{~kg}, 2(28 \%)$ consignments infested; 1997, 6 consignments, $10,576 \mathrm{~kg}, 2$ (33\%) consignments infested; 1998, no consignments imported. Most consignments were imported between August and October of each year.

TABLE 1: The response of diamondback moth strains to alpha-cypermethrin using a leaf dip bioassay.

\begin{tabular}{|c|c|c|c|c|c|}
\hline Strain & $\mathrm{n}$ & Slope+SE & $\mathrm{LC}_{50}{ }^{1}$ & $95 \% \mathrm{CI}$ & $\mathrm{RR}^{2}$ \\
\hline Local susceptible & 360 & 1.660 .18 & 0.002 & $0.001-0.002$ & - \\
\hline Imported resistant & 320 & $\begin{array}{ll}1.91 & 0.27\end{array}$ & 1.43 & 1.14-1.89 & 715 \\
\hline Hybrid & 386 & 1.290 .15 & 0.38 & $0.18-1.17$ & 190 \\
\hline Backcross & 475 & $0.88 \quad 0.10$ & 0.17 & $0.11-0.27$ & 85 \\
\hline
\end{tabular}

${ }^{1} \mathrm{mg}$ ai/litre.

${ }^{2}$ resistance ratio. 


\section{Bioassays}

The susceptible reference strain collected from Harewood was 715-fold more susceptible to alpha-cypermethrin than the imported resistant strain at the $\mathrm{LC}_{50}$ (Table 1). Slopes for the regressions were comparable.

\section{Hybrid strains}

Data for the reciprocal crosses were pooled for analysis since comparable mortality occurred at each concentration tested. The susceptible reference strain was 190 -fold more susceptible than the hybrid strain, and the susceptible reference strain was 85 -fold more susceptible than the progeny of the backcross between the hybrid strain and susceptible reference strain (Table 1). Slopes for the hybrid and backcross regressions were lower than those for the parent strains.

There were no significant differences $(\mathrm{P}>0.05)$ between the duration of larval or pupal development or the number of adults produced and their longevity for the susceptible, resistant and hybrid strains (Table 2).

\section{TABLE 2: The development, longevity and fecundity of diamondback moth strains.}

\begin{tabular}{lcccccccc}
\hline Strain & $\begin{array}{c}\text { Larval period } \\
\text { days }+ \text { SE }\end{array}$ & \multicolumn{2}{c}{$\begin{array}{c}\text { Pupal period } \\
\text { days }+ \text { SE }\end{array}$} & \multicolumn{2}{c}{$\begin{array}{c}\text { Adults } \\
\text { No. }+ \text { SE }\end{array}$} & \multicolumn{2}{c}{$\begin{array}{c}\text { Adult longevity } \\
\text { days }+ \text { SE }\end{array}$} \\
\hline Local susceptible & 5.9 & 0.25 & 5.50 & 0.035 & 356 & 25.4 & 10.4 & 0.49 \\
Imported resistant & 5.7 & 0.14 & 4.65 & 0.177 & 368 & 19.7 & 9.6 & 0.88 \\
Hybrid & 6.1 & 0.42 & 4.85 & 0.176 & 339 & 20.7 & 9.8 & 0.64 \\
\hline
\end{tabular}

\section{DISCUSSION}

The local reference strain was considerably more susceptible to alpha-cypermthrin than the imported resistant strain. The local strain also proved to be more susceptible to some organophosphate and carbamate insecticides than the imported strain (Voice 1998). The levels of resistance detected in the imported strain were generally consistent with those found in Australia, viz., very high levels of resistance $(>500-$ fold) to pyrethroids and lower levels to organophosphates and carbamates.

The potential to import insecticide resistant diamondback moth into New Zealand clearly exists. Although the resistance status of diamondback moth in a "normal' consignment of broccoli was not determined, it is possible that live individuals found on broccoli by MAF Quarantine inspections in recent years were resistant to insecticides since intensive spraying is common in major vegetable production areas, e.g. Queensland. It would not be unreasonable to assume that the box of broccoli obtained from a Brisbane market for this study was typical of broccoli grown in that area. Because diamondback moth is not an actionable quarantine pest and fumigation of consignments to kill contaminant insects is not required, live insects could readily enter New Zealand.

For resistant genes to spread from imported insects, a route from imported consignments to brassica crops would have to be probable. If consignments contained pupae or pre-pupal forms then, with further development, moths could emerge at any point in the supply chain and spread to brassicas, either to nearby home gardens or commercial crops. Diamondback moth has a high capacity to spread between local populations and over longer distances (Caprio and Tabashnik 1992). It has been suggested that even if the flow of resistant alleles was relatively low (e.g. $<2 \%$ ) this would still be sufficient to facilitate the rapid spread of resistance among susceptible populations (Caprio and Tabashnik 1992).

When the local and imported strains were interbred, lower levels of resistance to alpha- cypermethrin were expressed by the offspring. Besides confirming that the two strains were reproductively compatible, that resistance could be transferred and that it was not sex-linked (offspring of reciprocal crosses responded similarly), little further can be construed about the genetic status of the resistance. The backcross of 
$\mathrm{F}_{1}$ hybrids with parents did not yield a 1:1 segregation of phenotypes typical of resistance conferred by a singe gene. Pyrethroid resistance in diamondback moth has previously been shown to be polygenic (Liu et al. 1981) and these results would support this.

Back crossing resistant hybrids with susceptible parents further lowered the level of resistance expressed by the offspring. This suggests that, if there was little or no selection pressure that favoured the resistant alleles, the frequency of those alleles would decline even further in successive generations. By contrast, if resistant hybrids were exposed to selection pressure, then the proportion of resistant alleles in the population could increase and may eventually result in a population that could not be controlled at the recommended field application rate. That the resistant hybrids suffered no fitness disadvantage, at least for the characters examined, would further enhance their ability to survive under selection pressure.

Though this study has not investigated the likelihood or risk of imported resistance establishing in diamondback moth in New Zealand, it indicates that pyrethroid resistance can be conferred to a local susceptible strain from an imported strain. An analysis of the risk of importing resistance and its impact would clearly be valuable.

\section{ACKNOWLEDGEMENTS}

The support provided to David Voice by the Ministry of Agriculture and Forestry is gratefully acknowledged.

\section{REFERENCES}

Baker, G., 1994. Insecticidal resistance in Plutella xylostella (Lepidoptera: Plutellidae) populations in South Australia. RIRDC National Workshop-Managing insecticide resistance in diamondback moth. Pp 11-13.

Bell, P.D. and Fenemore, P.G., 1990. Insecticide resistance in diamondback moth in New Zealand. Proc. 43rd Weed and Pest Control Conf.: 31-34.

Cameron, P.J., Shelton, A.M., Walker, G.P. and Tang, J.D., 1997. Comparative insecticide resistance of New Zealand and North American populations of diamondback moth, Plutella xylostella (Lepidoptera: Plutellidae). N.Z. J. Crop Hort. Science 25: 117-122.

Caprio, M.A. and Tabashnik, B.E., 1992. Gene flow accelerates local adaption among finite populations: simulating the evolution of insecticide resistance. J. Econ. Entomol. 85: 611-620.

Chapman, R.B. 1990. Management of insecticide resistance in New Zealand. Pp 4351 In: New Zealand Applied Entomology, R.R. Scott (Ed.); Bulletin of the Entomological Society of New Zealand: 10.

Endersby, N. and Ridland, P., 1994. Historical profile of brassica production in Victoria and the development of insecticide resistance in diamondback moth. RIRDC National Workshop: Managing insecticide resistance in diamondback moth. Pp 15-19.

Heisswolf, S., 1994. Managing diamondback moth resistance in South East Queensland. RIRDC National Workshop: Managing insecticide resistance in diamondback moth. Pp 5-10.

Liu, Ming-Yie, Tzeng, Ying-Jeh and Sun, Chih-Ning, 1981. Diamondback moth resistance to several synthetic pyrethroids. J. Econ. Entomol. 74: 393-396.

Robertson, J.L., Russell, R.M. and Savin, N.E., 1980. POLO: A Users Guide to Probit or Logit Analysis. Berkeley, Pacific Southwest Forest and Range Experimental Station. 14 p.

Tabashnik, B.E. and Cushing, N.L., 1987. Diamondback moth (Lepidoptera: Plutellidae) resistance to insecticides in Hawaii: intra-island variation and cross-resistance. $J$. Econ. Entomol. 80: 1091-1099.

Talekar, N.S. and Shelton, A.M., 1993. Biology, ecology and management of the diamondback moth. Ann. Rev. Entomol. 38: 275-301.

Voice, D.G., 1998. Insecticide resistance in diamondback moth Plutella xylostella (L.) in Canterbury, New Zealand. Unpublished M. Applied Science thesis, Lincoln University. 97 pp. 